\title{
Organic Solvent's Effect in the Deposition of Platinum Particles on MWCNTs for Oxygen Reduction Reaction
}

\author{
Carolina Silva-Carrillo, ${ }^{1}$ Edgar Alonso Reynoso-Soto, ${ }^{1}$ Rosa María Félix-Navarro, ${ }^{1}$ \\ Shu Wai Lin-Ho, ${ }^{1}$ Aline Díaz-Rivera, ${ }^{1}$ Francisco Paraguay-Delgado, ${ }^{2}$ \\ José Álvaro Chávez-Carvayar, ${ }^{3}$ and Gabriel Alonso-Núñez ${ }^{4}$ \\ ${ }^{1}$ Centro de Graduados e Investigación, Instituto Tecnológico de Tijuana, Apartado Postal 1166, 22000 Tijuana, BC, Mexico \\ ${ }^{2}$ Centro de Investigación en Materiales Avanzados, Miguel de Cervantes 120, 31109 Chihuahua, CHIH, Mexico \\ ${ }^{3}$ Instituto de Investigación en Materiales, Universidad Nacional Autónoma de México, Circuito Exterior, Ciudad Universitaria, \\ 04510 Coyoacán, DF, Mexico \\ ${ }^{4}$ Centro de Nanociencias y Nanotecnología, Universidad Nacional Autónoma de México, Km 107 Carretera Tijuana-Ensenada, \\ Apartado Postal 356, 22800 Ensenada, BC, Mexico
}

Correspondence should be addressed to Edgar Alonso Reynoso-Soto; edgar.alonso@tectijuana.mx and Rosa María Félix-Navarro; rmfelix@tectijuana.mx

Received 24 July 2015; Revised 9 February 2016; Accepted 14 February 2016

Academic Editor: Xiao-Yu Yang

Copyright (c) 2016 Carolina Silva-Carrillo et al. This is an open access article distributed under the Creative Commons Attribution License, which permits unrestricted use, distribution, and reproduction in any medium, provided the original work is properly cited.

\begin{abstract}
We reported the synthesis of platinum particles anchored on the surface of multiwall carbon nanotubes (MWCNTs). The synthesis of platinum particles was carried out by microemulsion method using hexadecyltrimethylammonium bromide (CTAB) as surfactant to enhance the dispersion of platinum particles in hexane (C6), heptane (C7), and octane (C8) solutions. The effects of the microemulsion dispersion medium on the synthesis of platinum particles on MWCNTs (MWCNT/Pt) hybrid materials and their catalytic activities of the oxygen reduction reaction (ORR) in $\mathrm{HClO}_{4}$ were investigated. The anchored platinum particles showed good dispersion on carbon nanotubes surface with the average particle sizes of $2.65 \pm 0.60,2.89 \pm 0.68$, and $0.97 \pm 0.29 \mathrm{~nm}$ for the dispersion medium of C6, C7, and C8, respectively. The experimental results of ORR experiments indicated a relationship between the size and the dispersion media of the platinum particles; also the catalytic activity of the anchored platinum on MWCNT particles strongly depends on the dispersion medium employed in the microemulsion process.
\end{abstract}

\section{Introduction}

A fuel cell is an electrochemical device which converts free energy of a chemical reaction directly into electrical energy [1]. The main advantages of fuel cells are their high efficiency for electricity production of about $60 \%$ and practically zero emissions [2]. The cathode compartment is very important for the fuel cell because it is where the oxygen reduction reaction (ORR) takes place. The ORR is a sluggish reaction that consumes about $90 \%$ of total Pt content in PEM fuel cells [3]. The sluggish kinetics of the ORR are the main factor affecting the energy conversion efficiency of fuel cells $[4,5]$. Improvement of the efficiency of the catalyst by the development of Pt nanoparticles supported on carbonaceous materials with high surface area has been proposed as one of the most effective approaches to reduce the Pt contents with good activity for the ORR [6-8]. Surface oxidation of Vulcan Carbon materials as support for platinum nanoparticles can also increase the hydrophilicity of the surface, which can result in the decrease of gas permeability, as the pores become more likely to be filled with liquid water that can hinder gas transport [9]. Due to their unique electrical and structural properties, carbon nanotubes (CNTs) are an attractive support material for Pt nanoparticles (Pt NPs). Carbon nanotubes have demonstrated the ability to carry large current densities and fast electron transfer kinetics when used for electrochemical applications [10]. 
There are different methods to synthesize CNTs decorated with platinum nanoparticles such as colloidal method [11], microwave method [12, 13], chemical reduction [14], polyols method [15, 16], sputter technique [17], and microemulsion methods [18]. The microemulsions are thermodynamically stable colloidal dispersion constituted of a polar and a nonpolar solvent coexisting in a single phase with well-defined hydrophobic and hydrophilic domains stabilized by a monolayer of surfactant molecules $[19,20]$. Water-in-oil microemulsions are employed to produce ultrafine metal particles by precipitation with a narrow particle size distribution. In general, two microemulsions of same composition but containing different reactants with $10 \%$ in water are mixed and the precipitate is then isolated. This technique uses a nonpolar microemulsion in which the water droplets can be regarded as microreactors [20-22]. In recent decades researches have been focused on the areas of understanding the effects of changing diversified emulsion parameters such as surfactant molar ratio $\left(W_{o}\right)$, temperature, oil phase, and $\mathrm{pH}$ on the size, shape, and number of synthesized particles [23-26]. Oil phase plays an important role in the synthesis of metallic particle by microemulsion, because oil phase controls the interaction in the assembly of surfactant molecules to produce a supramolecular structure as reported by several authors [27-31]. The interactions between oil phase and surfactant hydrocarbon chains control the diffusion and mobility of reactants in the nucleation stage: formation and growth of particles. The oil phase causes an effect on the particle growth rate; this is due to the fact that the molecular volume of the solvent produces a variation on intermicellar exchange rate, which is given by the degree of interactions of the solvent molecules with the hydrocarbon chain of surfactant $[31,32]$.

In this work MWCNTs decorated with Pt particles (Pt NPs) were successfully prepared through water-in-oil microemulsion method using CTAB as surfactant and different organic solvents. The effects of hydrocarbon chain length on the catalytic properties of $\mathrm{Pt}$ nanoparticles synthesized were investigated. The MWCNT/Pt hybrid materials were used as catalysts for ORR using rotating disk electrode (RDE) by hydrodynamic voltammetry in acid medium; it clearly demonstrated the effect in catalytic activity with respect to the size of the platinum particles synthesized.

\section{Experimental}

2.1. Reagents. All chemicals used in this work were without further purification. Potassium hexachloroplatinate (IV) $\left(\mathrm{K}_{2} \mathrm{PtCl}_{6} \cdot 6 \mathrm{H}_{2} \mathrm{O}\right)$, sodium borohydride $\left(\mathrm{NaBH}_{4}\right)$, sodium citrate tribasic hydrate $\left(\mathrm{C}_{6} \mathrm{H}_{5} \mathrm{Na}_{3} \mathrm{O}_{7} \cdot x \mathrm{H}_{2} \mathrm{O}\right)$, hexadecyltrimethylammonium bromide (CTAB), and platinum on graphitized carbon (Pt/C, 20 wt.\% loading) were purchased from SigmaAldrich. Other reagents such as sulfuric acid $\left(\mathrm{H}_{2} \mathrm{SO}_{4}, 97 \%\right)$, nitric acid $\left(\mathrm{HNO}_{3}, 90 \%\right)$, 2-propanol $\left(\mathrm{C}_{2} \mathrm{H}_{8} \mathrm{O}, 99 \%\right)$, and hexane $\left(\mathrm{C}_{6} \mathrm{H}_{14}, 95 \%\right)$ were purchased from Fermont. All aqueous solutions were prepared with Milli-Q water $(18 \mathrm{M} \Omega$, Thermo Scientific). The MWCNTs used in this work were synthesized by spray pyrolysis technique and purified with nitric acid before being modified with platinum particles as reported previously by Alonso-Nuñez et al. [33].
2.2. Preparation of MWCNT/Pt NP. The synthesis of MWCNT/Pt NP hybrid material was carried out by microemulsion method. Microemulsion solution, named solution $\mathrm{A}$, was prepared using $\mathrm{CTAB}$ with a molar ratio $\left(W_{o}\right)$ of 91 in organic solvents of hexane (C6), heptane (C7), and octane (C8) mixed with 2-propanol and $\mathrm{H}_{2} \mathrm{O}$ in a ratio of $64: 32$ : $4 \%$ $\mathrm{v} / \mathrm{v}$. Then $20 \mathrm{mg}$ of MWCNTs was dispersed by ultrasound in $30 \mathrm{~mL}$ of solution $\mathrm{A}$ in a three-necked round bottom flask. The dispersion was stirred for $10 \mathrm{~min}$ at $60^{\circ} \mathrm{C}$. Afterwards, an aqueous solution of $500 \mathrm{mmol} \mathrm{L}^{-1}$ in sodium citrate tribasic hydrate and $500 \mathrm{mmol} \mathrm{L}^{-1}$ in sodium borohydride was mixed with $7.5 \mathrm{~mL}$ of solution $\mathrm{A}$; this solution was then added to the MWCNTs dispersion. After $15 \mathrm{~min}$ of stirring the MWCNTs dispersion with the reducing agents solution, a second microemulsion solution containing the platinum precursor was added; this precursor solution was prepared by mixing $2.5 \mathrm{~mL}$ of an aqueous solution of $\mathrm{K}_{2} \mathrm{PtCl}_{6} \cdot 6 \mathrm{H}_{2} \mathrm{O}$ with $7.5 \mathrm{~mL}$ of solution A. Finally the solution was left to react at $60^{\circ} \mathrm{C}$ for $90 \mathrm{~min}$.

After the overall reaction was completed, the MWCNT/Pt hybrid material was separated from the dispersion by filtration using a regenerated nitrocellulose membrane filter of $0.45 \mu \mathrm{m}$ pore diameter. The product was washed with 2propanol, deionized water, and acetone; this washing procedure was repeated several times to eliminate the remaining surfactant molecules. Finally, the MWCNT/Pt hybrid material was dried at $40^{\circ} \mathrm{C}$ for $2 \mathrm{~h}$ in an oven.

2.3. Characterization of MWCNT/Pt Hybrid Materials. Several techniques were used to characterize our synthesized hybrid materials; the size and the shape of Pt NP were studied by transmission electron microscopy (TEM) on a JEM 2200FS with spherical aberration corrector in probe mode, and the accelerating voltage was $200 \mathrm{kV}$. The sample preparation for TEM analysis was made by preparing dispersion of the MWCNT/Pt NP hybrid material in ethanol and placed in ultrasound for $3 \mathrm{~min}$ and then a drop of the dispersion was placed on a copper grid coated with a holey carbon film.

Thermogravimetric analysis (TGA) was performed on a TA-Instruments Q500 using a heating rate of $20^{\circ} \mathrm{C} / \mathrm{min}$ in an air flow of $60 \mathrm{~mL} / \mathrm{min}$.

The crystalline nature of Pt NP was studied by X-ray diffraction. The X-ray diffraction patterns were collected with a diffractometer, Siemens D5000, with $\mathrm{Cu} \mathrm{K} \alpha$ radiation (1.5404 $\AA$ ) by holding the silicon substrate with the clip of the sampler; the samples were scanned with a lapse of $1 \mathrm{~s}$ of collection per step.

2.4. Electrochemical Measurements. The electrochemical experiments were carried out with a potentiostat/galvanostat (Biologic VMP-300) electrochemical analyzer. All electrochemical experiments were performed at $25 \pm 0.5^{\circ} \mathrm{C}$ in a three-electrode cell in an electrolyte solution of $0.5 \mathrm{M} \mathrm{HClO}_{4}$. The reference electrode used was $\mathrm{Ag} / \mathrm{AgCl}$ sat. $\mathrm{KCl}, \mathrm{Pt}$ spiral wire as counter electrode and a rotating disk electrode (RDE) of Au was used as working electrode with a geometric area of $0.1257 \mathrm{~cm}^{2}$ and was modified with MWCNT/Pt hybrid material. To modify the RDE, its surface was first polished with alumina of $0.3 \mu \mathrm{m}$ slurry grade. After the RDE surface was 
polished, it was modified with a catalytic ink of MWCNT/Pt. The catalytic ink was prepared by suspending $5 \mathrm{wt} \%$ of our hybrid material in Nafion ${ }^{\circledR} /$ ethanol solution of ratio $78.6: 21.4 \% \mathrm{v} / \mathrm{v}$; this mixture was sonicated for $30 \mathrm{~min}$; after that, an aliquot of $80 \mu \mathrm{L}$ catalytic ink was placed on the RDE surface and dried in air at room temperature.

The determination of hydrogen adsorption/desorption process was carried out by cyclic voltammetry at a potential window from 1.3 to $-0.12 \mathrm{~V}$ with a scan rate of $100 \mathrm{mV} \mathrm{s}^{-1}$ using an aqueous solution of $\mathrm{HClO}_{4}$ at $0.5 \mathrm{~mol} \mathrm{~L}^{-1}$ under $\mathrm{N}_{2}$ atmosphere.

2.4.1. Electrocatalytic Activity Experiments for the ORR Using MWCNT/Pt NP Hybrid Material. The ORR experiments were carried out at the MWCNT/Pt NP hybrid material modified surface of RDE at rotating speeds of 50, 100, $250,500,750$, and $1000 \mathrm{rpm}$ with a scan rate of $5 \mathrm{mV} \mathrm{s}^{-1}$; $\mathrm{HClO}_{4}(\mathrm{aq})$ at $0.5 \mathrm{~mol} \mathrm{~L}^{-1}$ was used as the electrolyte solution. All working solutions were saturated with $\mathrm{O}_{2}$ for $20 \mathrm{~min}$ at constant $\mathrm{O}_{2}$ bubbling rate before experiments and during the measurements. All potentials shown in this work are in reference to standard hydrogen electrode (SHE).

\section{Results and Discussion}

3.1. Physicochemical Characterization of MWCNT/Pt NP Hybrid Materials. The morphology, size, and distribution of Pt NP supported on MWCNT were studied by transmission electron microscopy at STEM mode. In Figure 1, the low resolution TEM micrograph (Figures $1(\mathrm{a})$ and $1(\mathrm{c})$ ) of hybrid materials MWCNT/Pt-C6 (a) and MWCNT/Pt-C7 (b) can be clearly seen, where the exterior surfaces of the carbon nanotubes were decorated with well-dispersed fine nanoparticles in some MWCNT areas. The high resolution micrographs shown in Figures 1(b) and 1(d) revealed the aggregates of $\mathrm{Pt}$ NP on the MWCNT support.

For the nanomaterial MWCNT/Pt-C8 synthesized using octane as the emulsion media, the low resolution micrograph (Figure 1(e)) apparently showed the existence of platinum nanoparticles on carbon support; however, the high resolution micrograph (Figure 1(f)) indicated that there were fewer and smaller Pt nanoparticles at the MWCNT support.

In the analysis of the size, a decrease of particle size was observed with the increase of the number of carbon atoms in the emulsion liquid used for the synthesis. Furthermore, the formed Pt NP showed spherical morphology; the particle size distribution was calculated from these images. In the case of MWCNT/Pt-C6 hybrid material the size distribution is $2.65 \pm 0.60 \mathrm{~nm}$, while for the hybrid materials synthesized with heptane and octane the size distributions were observed to be $2.89 \pm 0.68 \mathrm{~nm}$ for $\mathrm{MWCNT} / \mathrm{Pt}-\mathrm{C} 7$ and $0.97 \pm 0.29 \mathrm{~nm}$ for MWCNT/Pt-C8. The particle size's decrease in the hybrid material MWCNT/Pt-C8 can be attributed to the emulsion liquid employed, because the chain length of the emulsion liquid generates an increase in the intermicellar exchange rate; this is due to the fact that as the chain length increases, it becomes progressively coiled and therefore its penetration in the surfactant layer becomes more difficult. Thus, the mutual interaction among surfactant tails
TABLE 1: Physicochemical characterizations of MWCNT/Pt hybrid materials.

\begin{tabular}{lccc}
\hline Sample & $\begin{array}{c}\text { Particle size by TEM } \\
(\mathrm{nm})\end{array}$ & $\begin{array}{c}\text { Pt content } \\
\text { Wt.\% }\end{array}$ & $\begin{array}{c}\text { Crystal size } \\
(\mathrm{nm})\end{array}$ \\
\hline MWCNT/Pt-C6 & $2.50 \pm 0.22$ & 12.35 & 2.43 \\
MWCNT/Pt-C7 & $2.89 \pm 0.68$ & 19.06 & 2.78 \\
MWCNT/Pt-C8 & $0.97 \pm 0.29$ & 8.73 & - \\
\hline
\end{tabular}

is stronger than the interaction between the surfactant tail and solvent molecules [28, 29]. It has been reported that a high intermicellar exchange rate increases the formation of micelles, and this will result in the formation of small particles $[27,34]$. In our case, the use of octane (C8) as solvent resulted in the formation of ultrafine Pt NP of $\sim 1 \mathrm{~nm}$.

The crystalline nature of the MWCNT/Pt hybrid materials was studied by X-ray diffraction (XRD) measurements as shown in Figure 2. The XRD pattern of the MWCNT/Pt hybrid material synthesized with all three organic solvents used, hexane, heptane, and octane, showed 002, 111, and 200 reflection planes at $26.0,40.2$, and 46.8 in $2 \theta$ range. The 002 reflection plane can be assigned to hexagonal graphitic carbon of MWCNTs. In the case of 111 and 200 reflection planes, they correspond to platinum with face-centered cubic (FCC) crystalline structure, which are anchored on MWCNTs surface. The low intensity and shape of diffraction peaks at 40.2 and 46.8 in the XRD pattern are due to the size of Pt NP. The intensity at 40.2 degrees occurs increasingly in the following order: MWCNT/Pt-C7 > MWCNT/Pt-C6 $>$ MWCNT/Pt-C8; this decrease in peak intensity may be due to a decrease in the number of steps $\mathrm{Pt}(111)$, while for the intensity at about 45 degrees, MWCNT/Pt-C7 > MWCNT/Pt-C8 > MWCNT/Pt-C6, it may suggest a decrease in the steps $\mathrm{Pt}(100)$. It is noticed that the MWCNT/Pt-C7 hybrid material shows a diffraction peak $\mathrm{Pt}(220)$ at 54.3 degrees; this may suggest the presence of steps $\mathrm{Pt}(110)$ [35].

Some authors report that the reactivity of $\mathrm{Pt}$ surface varies in the steps and the terraces surface, because the concentration of the electrons has lower work function [36]; for example, the adsorption of $\mathrm{OH}$ groups is highest in steps sites of $\mathrm{Pt}(100)$ inhibiting $\mathrm{O}-\mathrm{O}$ bond adsorption and rupture [37]. The crystal plane of the particles provides information and explains the reactivity and catalytic activity for the MWCNTs/Pt hybrid materials against ORR.

The crystal size was determined from XRD patterns by the Scherer Equation shown below:

$$
D=\frac{K \lambda}{\beta \cos \theta_{\beta}},
$$

(Scherer Equation)

where $D$ is the crystallite size, $\lambda$ is the $\mathrm{X}$-ray wavelength of $\mathrm{CuK}_{\alpha}$, and $K$ is a dimensionless shape factor with a value close to unity; it can be taken as 0.9 for full width at half maximum (FWHM) of spherical crystals with cubic unit cells [38]. The results of crystalline sizes are summarized in Table 1.

The metallic contents of MWCNTs/Pt hybrid materials were determined by thermogravimetric analysis. The thermograms of MWCNTs/Pt hybrid materials are shown in 


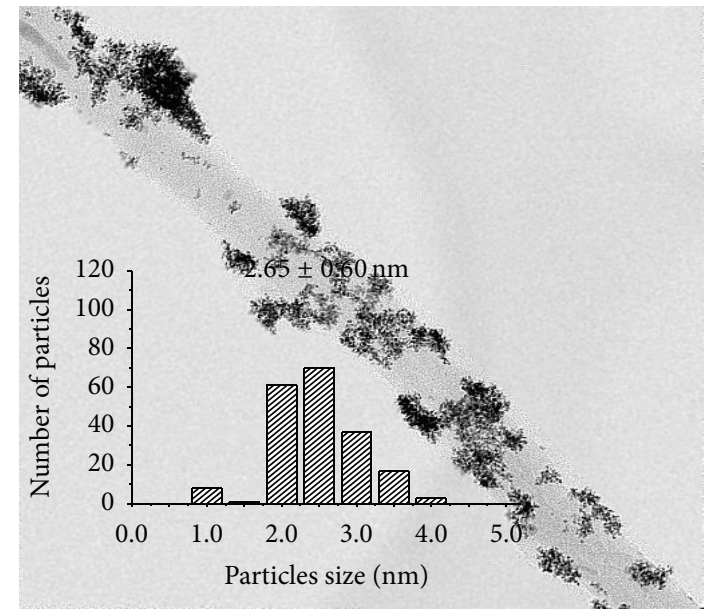

(a)

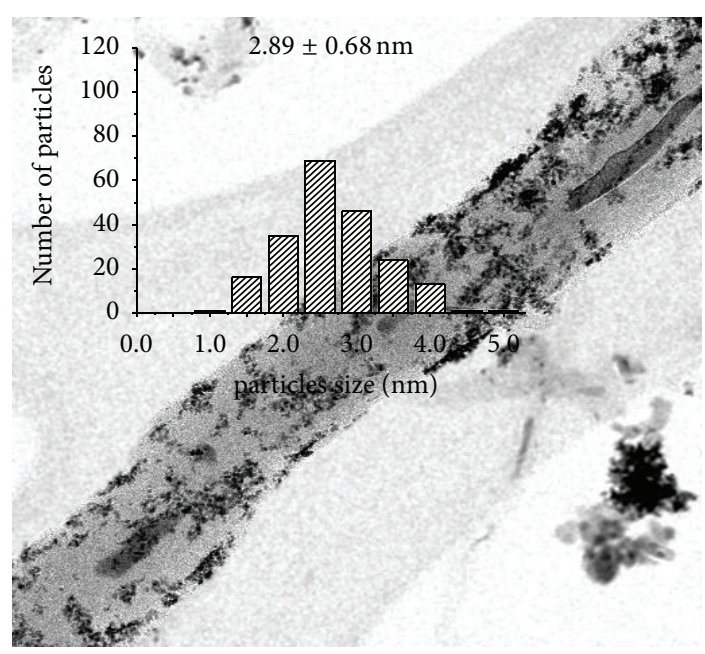

(c)

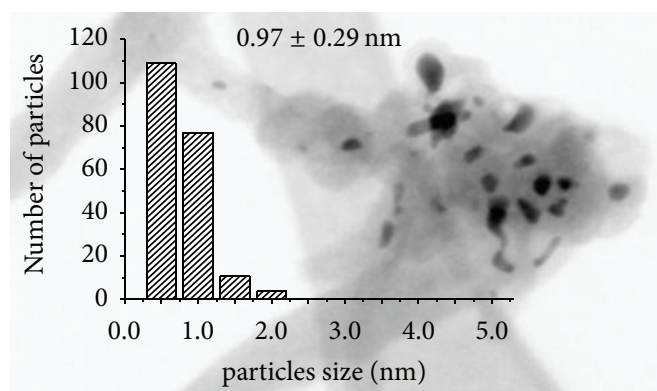

$100 \mathrm{~nm}$

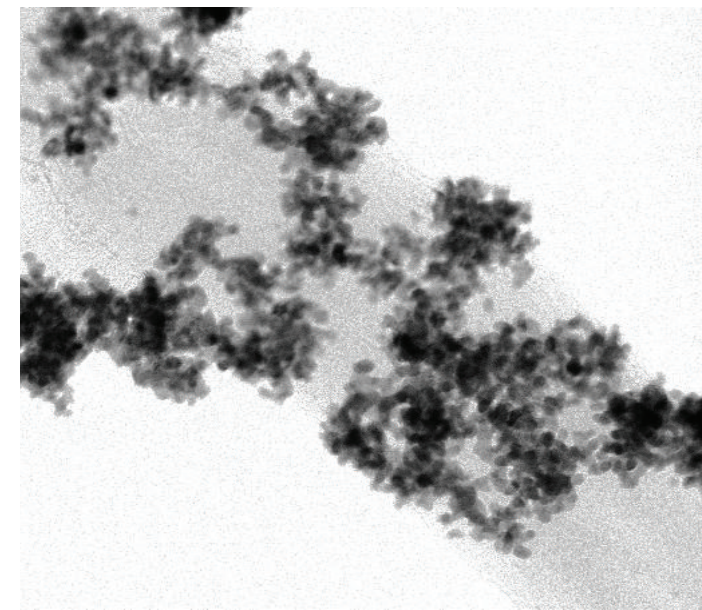

(b)

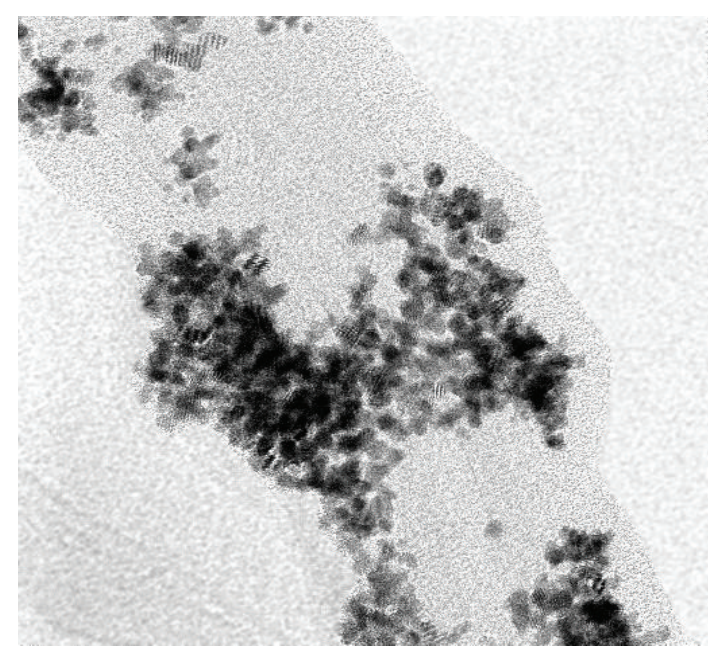

(d)

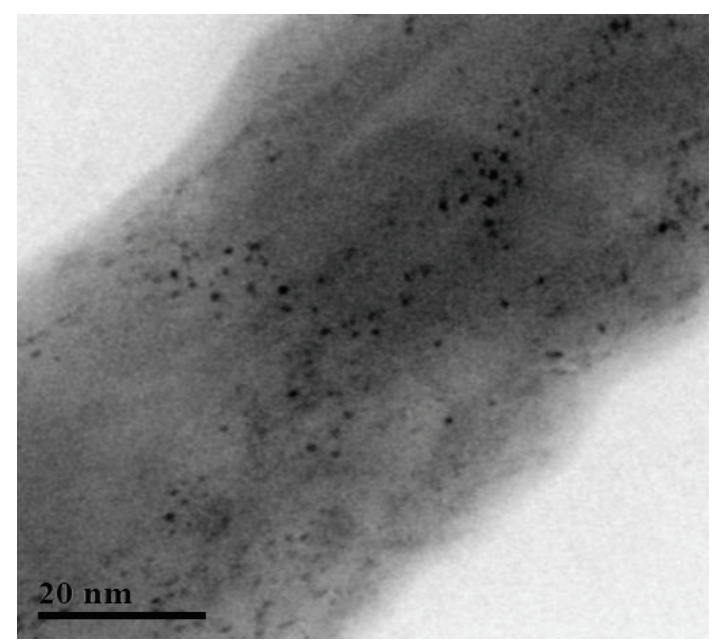

(f)

FIGURE 1: TEM images and histogram of MWCNT/Pt hybrid nanomaterials MWCNT/Pt-C6 (a and b), MWCNT/Pt-C7 (c and d), and MWCNT/Pt-C8 (e and f). 


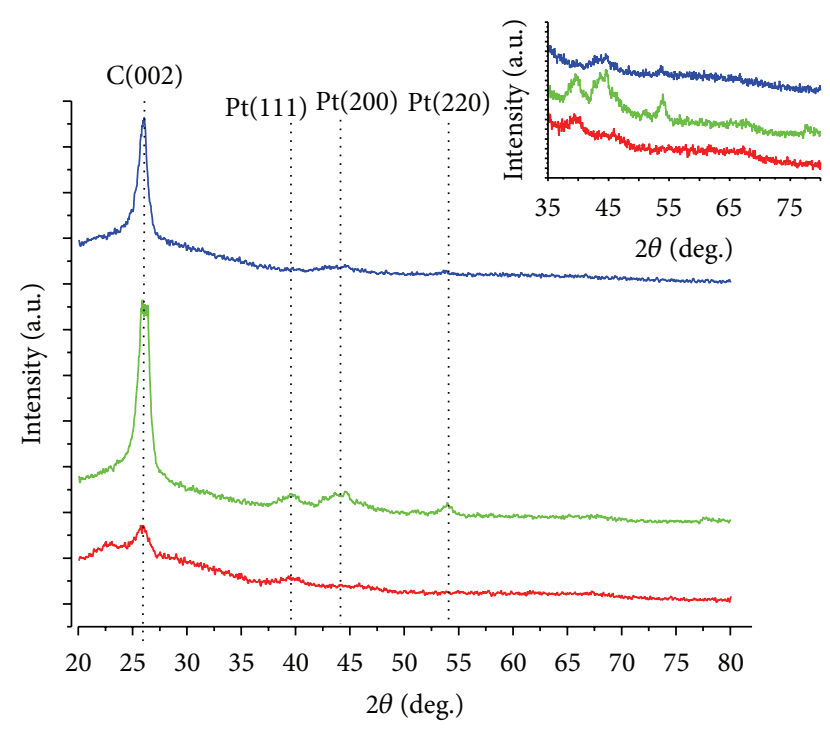

FIGURE 2: XRD patterns of MWCNT/Pt-C6 (red line), MWCNT/PtC7 (green line), and MWCNT/Pt-C8 (blue line) hybrid materials.

Figure 3. The MWCNTs/Pt hybrid materials showed decomposition in two steps; the first decomposition occurs at around $150^{\circ} \mathrm{C}$ with an average weight loss of 5 to $8 \%$; this is attributed to thermal decomposition of carbonaceous functional groups $(\mathrm{C}-\mathrm{O}, \mathrm{C}=\mathrm{O}$, and $\mathrm{O}-\mathrm{C}=\mathrm{O})$ created on the surface of MWCNTs by the chemical oxidation of $\mathrm{C}=\mathrm{C}$ double bonds during acid treatment of MWCNT [39]. This first decomposition step was not observed for MWCNTs without acid treatment as shown in Figure 3 for comparison purposes. The second decomposition was observed for all hybrid materials which correspond to the thermal oxidation of MWCNTs between 200 and $650^{\circ} \mathrm{C}$, leaving residues of 12.35 wt.\%, 19.06 wt. $\%$, and 8.73 wt.\% which corresponded to the platinum wt.\% in MWCNT/Pt-C6, MWCNT/Pt-C7, and MWCNT/Pt-C8, respectively. The variation on the metallic contents can be attributed to the change of micelle exchange rate during formation and deposition of $\mathrm{Pt} \mathrm{NP}$ on the carbon nanotubes surface. Some authors reported that an increase in number of particles formed was due to an increase in the micelle exchange rate under the condition of employing organic solvent with high number of carbon atoms; however, when the platinum particles were synthesized in the presence of MWCNT, the reaction is controlled by the microemulsion and the curved surface of nanotubes as reported by Staykov et al. [40]; the surface of MWCNTs will control the covalent character of binding between microemulsion and particles, as a result of the electron density shift from the nanotubes and the particles to the region between the metal and the carbon. This interaction causes changes in the thermal stability of MWCNTs; thus it shows a shift to low decomposition temperatures of the nanotube.

In Table 1 the physicochemical characteristics of the MWCNTs/Pt hybrid materials are summarized. A relationship between size and contents of platinum particles with the organic solvent employed in the synthesis can be seen clearly.

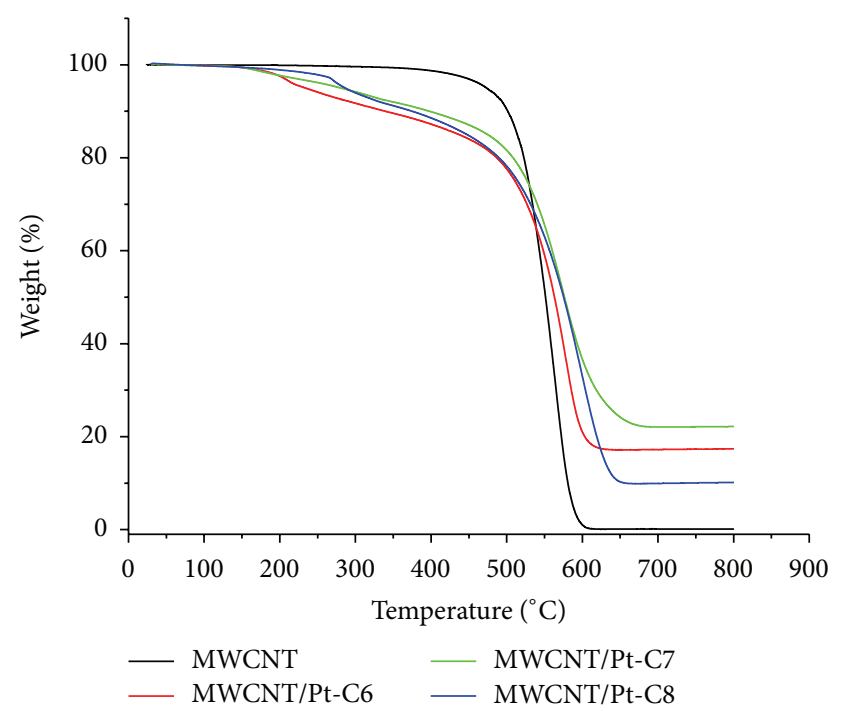

Figure 3: Thermogravimetric analysis of MWCNT (black line), MWCNT/Pt-C6 (red line), MWCNT/Pt-C7 (green line), and MWCNT/Pt-C8 (blue line) hybrid materials.

Bagwe and Khilar [27] reported the effects of the type of organic solvents such as cyclohexane, heptane, and decane on absorption and particle size of silver NPs synthesis via inverse microemulsion. They observed that the intermicellar exchange rate changed upon changing the type of organic solvent, which was responsible for final changes in particle size. Also Petit et al. [41] found that the replacement of cyclohexane by isooctane decreased silver's particle size. In our present work, the trend was observed to be consistent with that described in the literatures when heptane and octane were employed as organic solvents but not in the case of hexane; this might be due to the low viscosity of hexane; thus it may not have good interaction with the surfactant chain.

\subsection{Electrochemical Performance of MWCNT/Pt Hybrid} Materials. The electrochemical characterization of MWCNT/Pt hybrid materials was carried out by CV in the hydrogen adsorption/desorption experiments. Figure 4(a) shows the CV curves for the MWCNT/Pt hybrid materials and $\mathrm{Pt} / \mathrm{C}$ commercial catalyst (Pt loading $20 \mathrm{wt} . \%$ ) measured in $\mathrm{N}_{2}$ saturated $0.5 \mathrm{M} \mathrm{HClO}_{4}$ solution at a scan rate of $100 \mathrm{mV} \mathrm{s}^{-1}$. The CV curves show three characteristic potential regions: the hydrogen adsorption and desorption region $(0.0$ to $0.2 \mathrm{~V})$, double layer plateau region $(0.2$ to $0.4 \mathrm{~V})$, and the formation and reduction of surface Pt oxide $(0.5$ to $0.8 \mathrm{~V})$. The onset potential of $\mathrm{OH}_{\mathrm{ads}}$ formation and the peak potential for the reduction of $\mathrm{Pt}-\mathrm{OH}_{\mathrm{ads}}$ are of particular interest. In the cyclic voltammograms, the dependence of the particle size and content on the intensity of the $\mathrm{Pt}-\mathrm{OH}_{\mathrm{ads}}$ bond can clearly be seen. The MWCNT/Pt-C7 hybrid material shows the strong absorption of oxygen and more negative potential for the reduction of $\mathrm{Pt}-\mathrm{OH}_{\mathrm{ads}}$. The study of dependence of the peak potential of $\mathrm{Pt}-\mathrm{OH}_{\mathrm{ads}}$ bond on the $\mathrm{Pt}$ loading on MWCNTs is shown in Figure 4(b). It can be observed that the peak potential of the $\mathrm{Pt}-\mathrm{OH}_{\mathrm{ads}}$ reduction shifts 


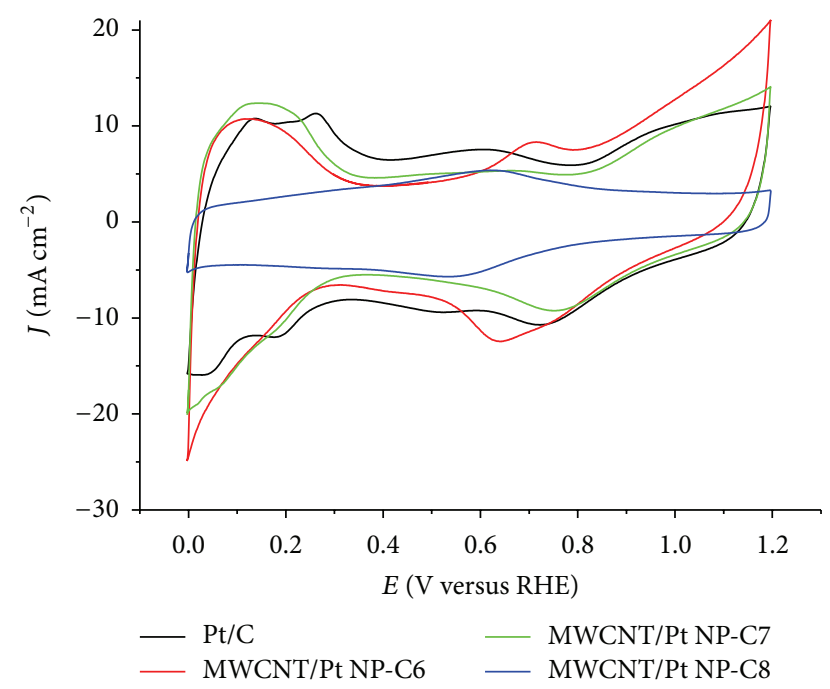

(a)

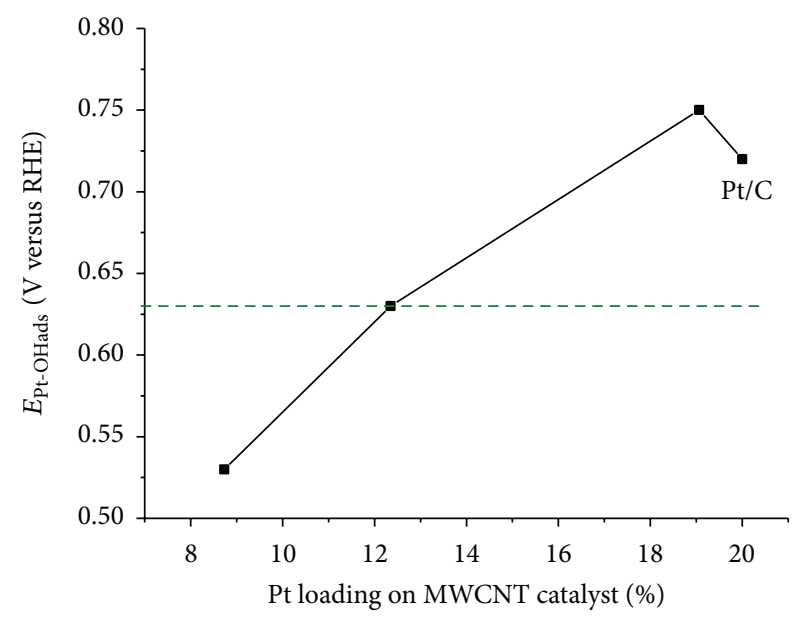

(b)

FIgUre 4: Cyclic voltammograms of MWCNT/Pt hybrid materials and $\mathrm{Pt} / \mathrm{C}$ catalysts in $0.5 \mathrm{M} \mathrm{HClO}_{4}$, with scan rate of $100 \mathrm{mV} \mathrm{s}^{-1}$ at $25^{\circ} \mathrm{C}$ (a). Graph of the relationship of the potential of $\mathrm{OH}$ adsorption on Pt NP versus Pt loading (b).

significantly toward more positive values as the Pt loading is above 20 wt.\% on MWCNTs. It is evident that the loading and the density of Pt NP on MWCNT significantly affect the chemical adsorption of oxygen-containing species by a reduction of the oxophilicity as reported by Wang et al. [42].

The electroactive surface area was also determined from the hydrogen adsorption and desorption region ( 0.0 to $0.2 \mathrm{~V})$. The charge values $\left(Q_{\mathrm{H}}\right)$ measured under the hydrogen adsorption curves are compared in Table 2 . We see an increase in the electrochemically active area (EASA) related to the metallic content and the particle size, which in turn is related to the type of organic solvent used in the synthesis and its interaction with surfactant molecules due to a change of the intermicellar exchange rate as discussed before [43]. for ORR. The electrocatalytic activity of Pt NP supported on
TABLE 2: Determination of electrochemical active surface area (EASA) of Pt.

\begin{tabular}{lccc}
\hline Sample & $\begin{array}{c}\text { Loading of Pt } \\
(\mathrm{mg})\end{array}$ & $\begin{array}{c}\mathrm{Q}_{\mathrm{H}} \\
(\mathrm{mC})\end{array}$ & $\begin{array}{c}\text { EASA } \\
\left(\mathrm{cm}^{2} \mathrm{mg}^{-1} \mathrm{Pt}\right)\end{array}$ \\
\hline MWCNT/Pt-C6 & 0.035 & 1.23 & 145.80 \\
MWCNT/Pt-C7 & 0.055 & 2.05 & 176.01 \\
MWCNT/Pt-C8 & 0.025 & - & - \\
Pt/C & 0.058 & 1.22 & 107.19 \\
\hline
\end{tabular}

MWCNT was evaluated in the ORR by linear voltammetry measurements. Figure 5 shows the linear polarization curves for MWCNT/Pt-C6, MWCNT/Pt-C7, and MWCNT/Pt-C8 hybrid materials obtained from ORR in $1.0 \mathrm{M} \mathrm{HClO}_{4}$ solution at various rotation speeds of the RDE. From linear polarization curves of all materials, three different characteristic regions were observed only at low rotational speeds. When the $\mathrm{RDE}$ rotation rate is increased, limiting currents are also increased due to the increment of oxygen diffusion through the electrode surface as reported in the literature [44]. However, limiting currents are not observed at high rotation speeds; this may indicate that the diffusion and the kinetic processes are both dominating in this step for the catalysis in ORR.

The linear voltammetry results of MWCNT/Pt hybrid material for ORR in $0.5 \mathrm{M} \mathrm{HClO}_{4}$ are summarized in Figure 6. To compare the ORR catalytic activity, all the currents are normalized to the mass of platinum that had been drop-coated onto the electrode. Among all these hybrid materials, MWCNT/Pt-C7 shows the highest activity in the kinetic controlled region for the ORR, much higher than the $\mathrm{Pt} / \mathrm{C}$ commercial catalyst, while MWCNT/Pt-C8 shows the worst ORR performance as shown in Figure 7.

The values of half-wave potential $\left(E_{1 / 2}\right)$ for ORR with MWCNT/Pt-C6, MWCNT/Pt-C7, and MWCNT/Pt-C8 hybrid materials are $0.62,0.76$, and $0.52 \mathrm{~V}$, respectively, and $0.72 \mathrm{~V}$ for Pt/C commercial catalyst (20\% Pt-loaded activated carbon). The half-wave potential of the MWCNT/Pt NP-C7 and $\mathrm{Pt} / \mathrm{C}$ catalyst is shifted to higher potentials as compared to other catalysts reported in this work. This may indicate that a lower overpotential is required to efficiently catalyze the reduction of oxygen as suggested in previous publication [45].

The low catalytic activity of the hybrid material MWCNT/ Pt-C6 with respect to MWCNT/Pt-C7 and Pt/C commercial nanomaterials could be attributed to the less metallic $\mathrm{Pt}$ contents; this results in fewer active sites for $\mathrm{O}_{2}$ adsorption. On the other hand, hybrid material MWCNT/Pt-C8 shows the lower catalytic activity with respect to other materials used; this might be due to the adsorption of the $\mathrm{OH}$ groups of electrolyte in the steps $\mathrm{Pt}(100)$ that had smaller Pt nanoparticles of this nanomaterial; this would inhibit $\mathrm{O}_{2}$ adsorption on its surface $[36,37]$. These results agree with those reported by Shao et al. [46], where less than $2.1 \mathrm{~nm}$ particle sizes showed increase in energy of Pt-O bond; this may efficiently inhibit the oxygen reduction; therefore hybrid materials MWCNT/ $\mathrm{Pt}-\mathrm{C} 8$ and MWCNT/Pt-C7 show a lower specific mass value in the ORR compared to MWCNT/Pt-C7 and Pt/C which 


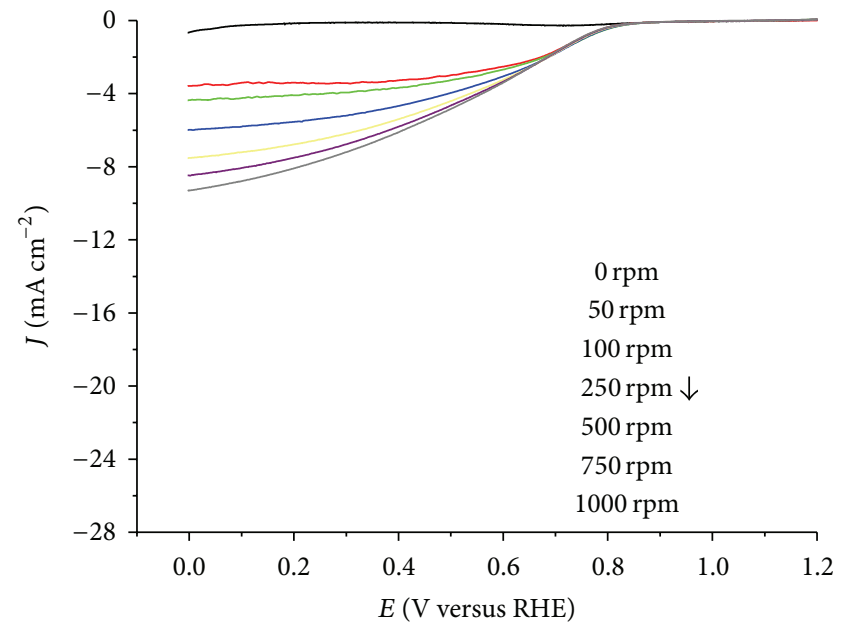

(a)

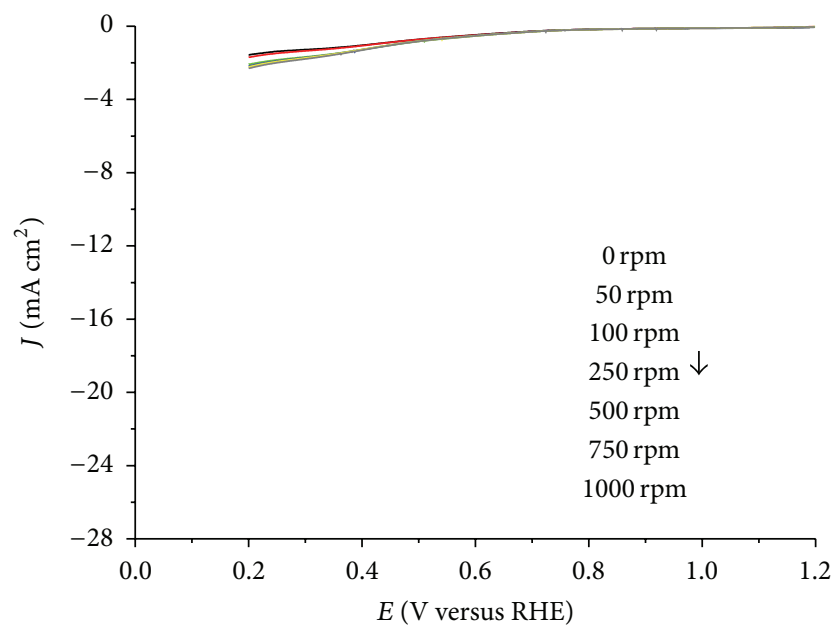

(c)

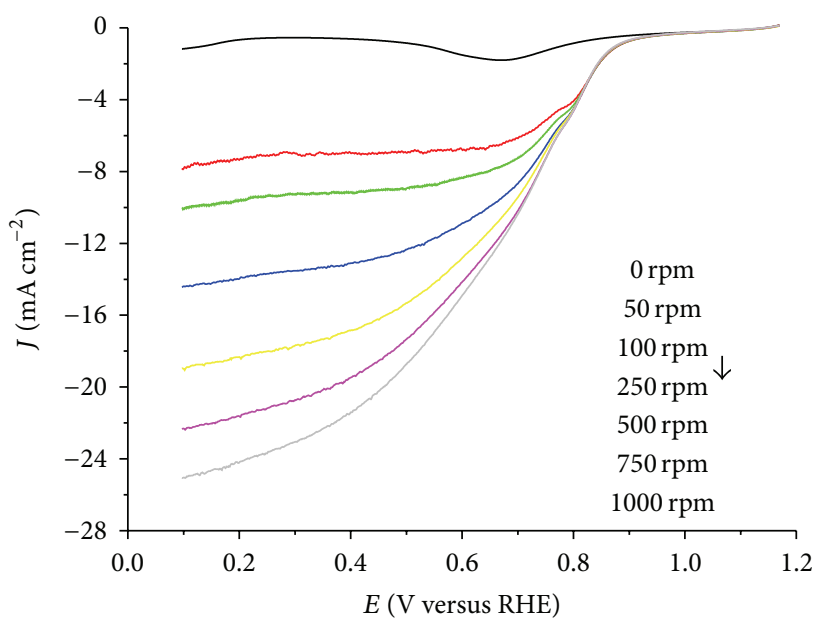

(b)

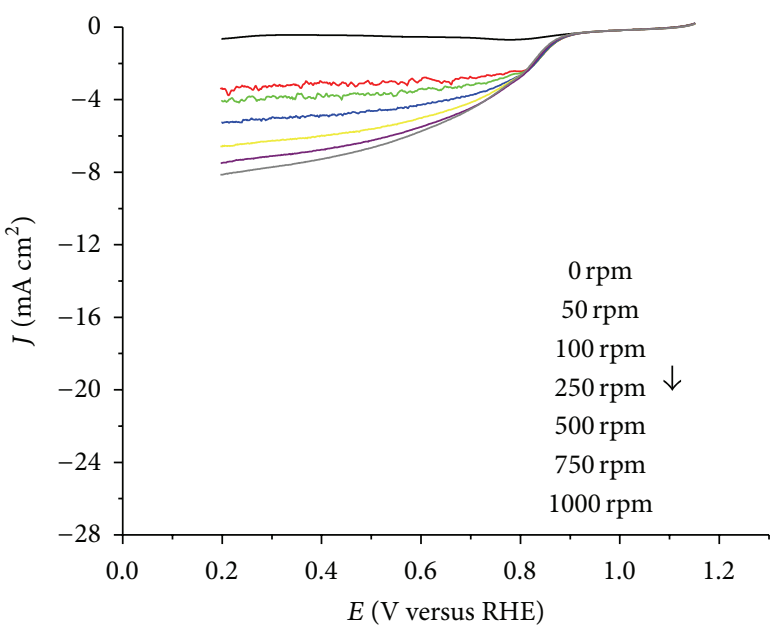

(d)

FIgURE 5: Linear voltammograms for ORR in $\mathrm{O}_{2}$ saturated solution of $0.5 \mathrm{M} \mathrm{HClO}_{4}$ at $25^{\circ} \mathrm{C}$ using $\mathrm{MWCNT} / \mathrm{Pt}-\mathrm{C} 6$ (a), MWCNT/Pt-C7 (b), MWCNT/Pt-C8 (c), and Pt/C commercial catalysts (d) at $5 \mathrm{mV} \mathrm{s}^{-1}$.

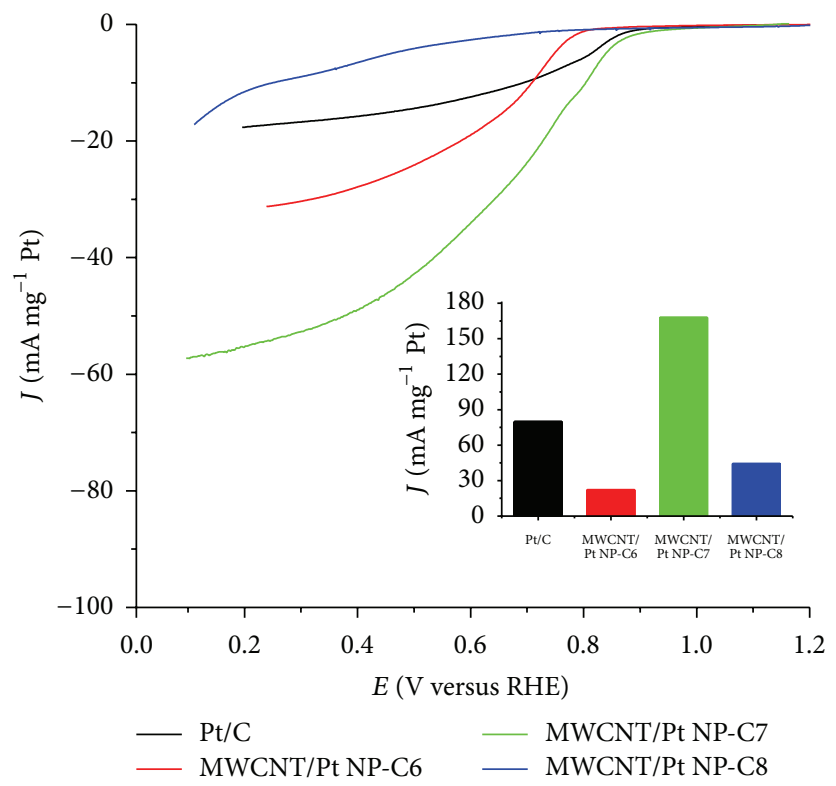

FIGURE 6: Current-potential curves for ORR in $\mathrm{O}_{2}$ saturated $0.5 \mathrm{M} \mathrm{HClO}_{4}$ at a rotating rate of $1000 \mathrm{rpm}$ with MWCNT/Pt-C6 (green line), MWCNT/Pt-C7 (blue line), MWCNT/Pt-C8 (red line), and Pt/C commercial (black line) catalysts at $25^{\circ} \mathrm{C}$ at $5 \mathrm{mV} \mathrm{s}^{-1}$. Insert: comparisons of the mass activities at $0.90 \mathrm{~V}$. 


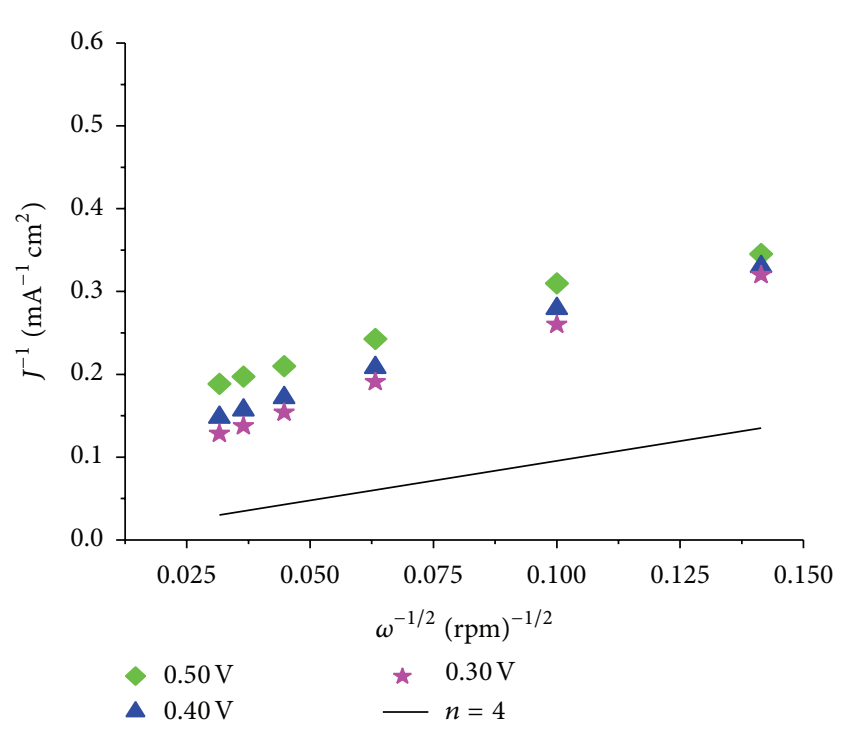

(a)

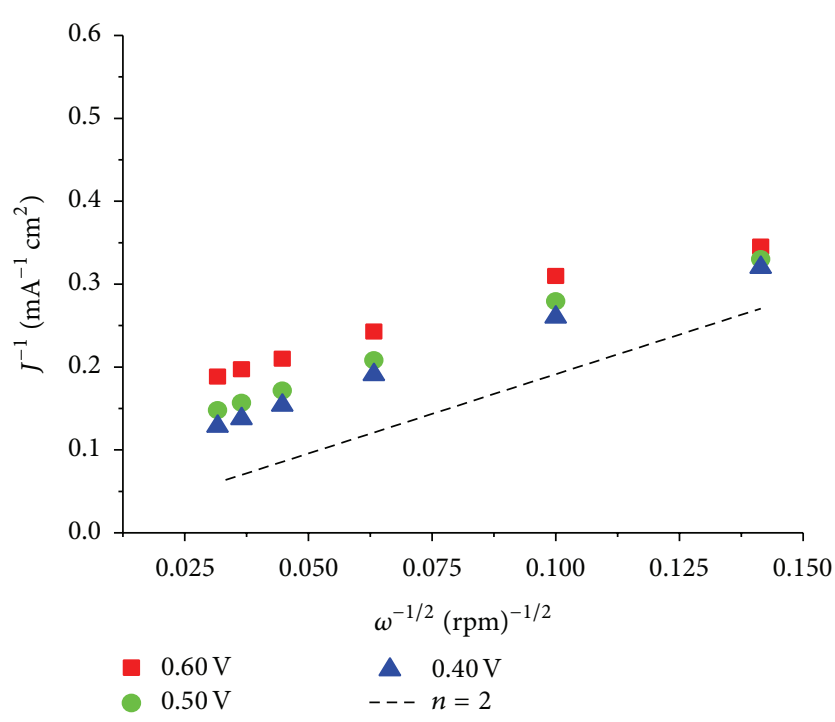

(c)

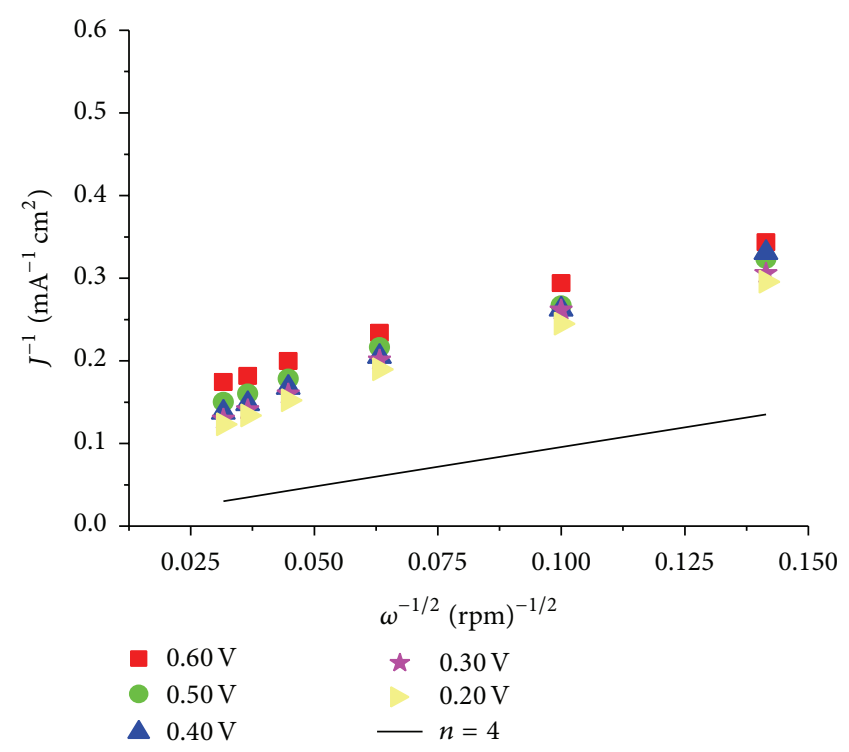

(b)

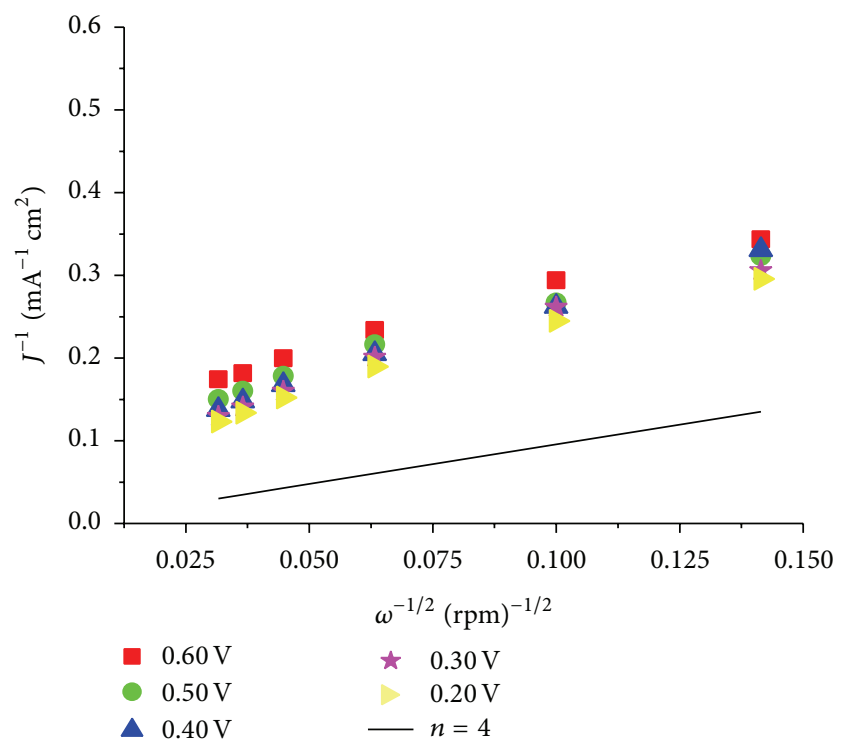

(d)

Figure 7: Koutecky-Levich plots for MWCNT/Pt-C6 (a), MWCNT/Pt-C7 (b), MWCNT/Pt-C8 (c), and Pt/C commercial catalyst (d) at various potentials in $\mathrm{O}_{2}$ saturated $0.5 \mathrm{M} \mathrm{HClO}_{4}$ solution with a scan rate of $5 \mathrm{mV} \mathrm{s}^{-1}$.

present the higher specific mass activity; this can be attributed to the lower Pt content in the first two hybrid materials, generating a smaller active area; this resulted in a lower mass transfer. The mass-specific activities values for MWCNT/Pt$\mathrm{C} 7$ hybrid materials and $\mathrm{Pt} / \mathrm{C}$ in this work are consistent with the values reported by Khudhayer et al. [47] and by Shrestha et al. [48].

In order to determine the kinetics of MWCNT/Pt hybrid materials for ORR, current-potential curves were analyzed using the Koutecky-Levich equation (see (1)), where $J$ is the experimentally observed current, $J_{k}$ and $J_{L}$ are the kinetic and diffusion-limited current densities, respectively, $n$ is the number of electrons transferred per molecule of $\mathrm{O}_{2}$ reduced, $\mathrm{F}$ is the Faraday constant $\left(96485 \mathrm{C} \mathrm{mol}^{-1}\right), D_{\mathrm{O}_{2}}$ is the diffusion coefficient for oxygen in $0.5 \mathrm{M} \mathrm{HClO}_{4}\left(1.85 \times 10^{-5} \mathrm{~cm}^{2} \mathrm{~s}^{-1}\right)$ solution, $\omega$ is the rotation rate in revolutions per minute (rpm), $C_{\mathrm{O}_{2}}$ is the concentration of dissolved oxygen in $0.5 \mathrm{M}$ $\mathrm{HClO}_{4}\left(1.13 \times 10^{-6} \mathrm{~mol} \mathrm{~cm}{ }^{-3}\right), v$ is the kinematic viscosity of electrolytes employed $\left(0.5 \mathrm{M} \mathrm{HClO}_{4}\right.$ is $\left.0.01 \mathrm{~cm}^{2} \mathrm{~s}^{-1}\right)$, and $k$ is the apparent electron transfer rate constant [49]:

$$
\frac{1}{J}=-\frac{1}{J_{k}}+\frac{1}{J_{L}}=\frac{1}{J_{k}}+\frac{1}{B \omega^{1 / 2}} .
$$

Consider $B=0.20 n F C_{\mathrm{O}_{2}}^{b} \nu^{-1 / 2} D_{\mathrm{O}_{2}}^{2 / 3} \omega^{1 / 2}$ and $J_{k}=n F \kappa$.

The plots of $1 / J$ versus $1 / \omega^{1 / 2}$ for each hybrid material are shown in Figure 7. From the Koutecky-Levich plots the number of electrons transferred to the ORR at different 
potentials with good linearity can be determined [50, 51]. The results indicate potential dependence on the number of transferred electrons for the ORR for the MWCNT/Pt-C6 and MWCNT/Pt-C8 hybrid materials; at low potential the reaction proceeds via two-electron transfer; this indicates the formation of $\mathrm{H}_{2} \mathrm{O}_{2}$, but at higher potential the reaction proceeds via four-electron transfer; this corresponds to the reduction of $\mathrm{O}_{2}$ to $\mathrm{H}_{2} \mathrm{O}$ as reported in the literatures [48-50]. In the case of the MWCNT/Pt-C7 material the $1 / \mathrm{J}$ versus $1 / \omega^{1 / 2}$ plot indicates that the reduction of oxygen occurs via four electrons in the potential range studied; it selectively promotes the formation of $\mathrm{H}_{2} \mathrm{O}$; this is similar to the $\mathrm{Pt} / \mathrm{C}$ commercial catalyst; oxygen reduction reaction is via three-electron transfer.

These experimental results of this work indicate a relationship between the size of the platinum particles and the catalytic activity for ORR. The MWCNT/Pt-C7 catalyst was found to be the most active for the ORR via a mechanism of four-electron transfer and the formation of $\mathrm{H}_{2} \mathrm{O}$ for the potential range studied. The particle size and crystal structure play an important role in the catalytic activity of the material. It is reported that the low-index crystallographic facets of Pt show an increase of catalytic activity for the ORR in order of $\mathrm{Pt}(100) \ll \operatorname{Pt}(111)<\operatorname{Pt}(110)$; other crystallographic facets can promote adverse effects for the adsorption of $\mathrm{OH}$ species on Pt facets that would block active sites for $\mathrm{O}_{2}$ adsorption and modify the ORR kinetics [51, 52]. There are reports demonstrating that $\mathrm{Pt}$ particles with sizes close to $3 \mathrm{~nm}$ exhibit the maximum catalytic activity for ORR [46, 53, 54]. It was determined that the particle size of MWCNT/Pt$\mathrm{C} 7$ catalysts was about $3 \mathrm{~nm}$; this catalyst may require a lower overpotential for the ORR and $E_{1 / 2}$ would be close to the value of the commercial $\mathrm{Pt} / \mathrm{C}$; thus it promotes ORR with a reaction mechanism via four-electron transfer.

\section{Conclusion}

The experimental results of our present work had revealed that there was dependence of the size and the contents of the platinum particles anchored on MWCNTs on the organic solvent used in microemulsion solution during the synthesis process. When the length of the hydrocarbon chain is greater than seven carbons, there is an increase in chain flexibility and interaction with hydrocarbon chain of the surfactant; this would modify the micellar exchange rate of the microemulsion process, and thus it would lead to the decrease of the particle size and its catalytic activity for the oxygen reduction reaction. The MWCNT/Pt-C7 catalyst shows good physicochemical and electrochemical properties and would be an ideal catalyst for use as the cathode material in the fuel cell.

\section{Conflict of Interests}

The authors declare that there is no conflict of interests regarding the publication of this paper.

\section{Acknowledgments}

The authors acknowledge the financial support of the Mexican Council of Science and Technology (CONACyT) under Grants nos. INFR-2013-224627 and RED-2012-194153 and Tecnológico Nacional de México (Grant no. 5232.14-P). Carolina Silva-Carrillo is grateful to CONACyT for providing the scholarship for her doctoral thesis research. Thanks are due to Nanotechnology National Lab, located at CIMAV, Chihuahua, Mexico, for electron microscopy study. The authors thank C. Ornelas, B. Trujillo, and R. Salinas for their technical help.

\section{References}

[1] H. Chen, T. N. Cong, W. Yang, C. Tan, Y. Li, and Y. Ding, "Progress in electrical energy storage system: a critical review," Progress in Natural Science: Materials International, vol. 19, no. 3, pp. 291-312, 2009.

[2] Y. Alyousef and K. Kendall, "Characterization of the electrochemical performance of micro-tubular solid oxide fuel cell (SOFC)," Journal of Taibah University for Science, vol. 2, pp. 1421, 2009.

[3] J. Zhang, "PEM fuel cells and platinum-based electrocatalysts," in Fuel Cells: Selected Entries from the Encyclopedia of Sustainability Science and Technology, K. D. Kreuer, Ed., p. 306, Springer, New York, NY, USA, 2013.

[4] X. Gong, S. Liu, C. Ouyang, P. Strasser, and R. Yang, "Nitrogenand phosphorus-doped biocarbon with enhanced electrocatalytic activity for oxygen reduction," ACS Catalysis, vol. 5, no. 2, pp. 920-927, 2015.

[5] B. Kang and J. Y. Lee, "Graphynes as promising cathode material of fuel cell: improvement of oxygen reduction efficiency," The Journal of Physical Chemistry C, vol. 118, no. 22, pp. 12035-12040, 2014.

[6] J. Zhang, S. Tang, L. Liao et al., "Improved catalytic activity of mixed platinum catalysts supported on various carbon nanomaterials," Journal of Power Sources, vol. 267, pp. 706-713, 2014.

[7] C. Gupta, P. H. Maheshwari, S. Sasikala, and R. B. Mathur, "Processing of pristine carbon nanotube supported platinum as catalyst for PEM fuel cell," Materials for Renewable and Sustainable Energy, vol. 3, no. 36, pp. 36-46, 2014.

[8] C. Galeano, J. C. Meier, M. Soorholtz et al., "Nitrogen-doped hollow carbon spheres as a support for platinum-based electrocatalysts," ACS Catalysis, vol. 4, no. 11, pp. 3856-3868, 2014.

[9] B. Avasarala, R. Moore, and P. Haldar, "Surface oxidation of carbon supports due to potential cycling under PEM fuel cell conditions," Electrochimica Acta, vol. 55, no. 16, pp. 4765-4771, 2010.

[10] N. Punbusayakul, S. Talapatra, L. Ci, W. Surareungchai, and P. M. Ajayan, "Double-walled carbon nanotube electrodes for electrochemical sensing," Electrochemical and Solid-State Letters, vol. 10, no. 5, pp. F13-F17, 2007.

[11] B. Escobar, R. Barbosa, M. M. Yoshida, and Y. Verde Gomez, "Carbon nanotubes as support of well dispersed platinum nanoparticles via colloidal synthesis," Journal of Power Sources, vol. 243, pp. 88-94, 2013.

[12] S. N. Stamatin, M. Borghei, S. M. Andersen et al., "Influence of different carbon nanostructures on the electrocatalytic activity 
and stability of Pt supported electrocatalysts," International Journal of Hydrogen Energy, vol. 39, no. 16, pp. 8215-8224, 2014.

[13] M. Rahsepar, M. Pakshir, and H. Kim, "Synthesis of multiwall carbon nanotubes with a high loading of Pt bya microwaveassisted impregnation method for use in the oxygenreduction reaction," Electrochimica Acta, vol. 108, pp. 769-775, 2013.

[14] M. S. Ahmed, D. Kim, and S. Jeon, "Covalently grafted platinum nanoparticles to multi walled carbon nanotubes for enhanced electrocatalytic oxygen reduction," Electrochimica Acta, vol. 92, pp. 168-175, 2013.

[15] S. N. Stamatin, M. Borghei, R. Dhiman et al., "Activity and stability studies of platinized multi-walled carbon nanotubes as fuel cell electrocatalysts," Applied Catalysis B: Environmental, vol. 162, pp. 289-299, 2015.

[16] K. Kardimi, T. Tsoufis, A. Tomou, B. J. Kooi, M. I. Prodromidis, and D. Gournis, "Synthesis and characterization of carbon nanotubes decorated with $\mathrm{Pt}$ and $\mathrm{PtRu}$ nanoparticles and assessment of their electrocatalytic performance," International Journal of Hydrogen Energy, vol. 37, no. 2, pp. 1243-1253, 2012.

[17] K. Jukk, J. Kozlova, P. Ritslaid, V. Sammelselg, N. Alexeyeva, and K. Tammeveski, "Sputter-deposited Pt nanoparticle/multiwalled carbon nanotube composite catalyst for oxygen reduction reaction," Journal of Electroanalytical Chemistry, vol. 708, pp. 31-38, 2013.

[18] N. Alexeyeva, K. Tammeveski, A. Lopez-Cudero, J. SollaGullón, and J. M. Feliu, "Electroreduction of oxygen on Pt nanoparticle/carbon nanotube nanocomposites in acid and alkaline solutions," Electrochimica Acta, vol. 55, no. 3, pp. 794-803, 2010.

[19] I. Danielsson and B. Lindman, "The definition of microemulsión," Colloids and Surfaces A: Physicochemical and Engineering Aspects, vol. 3, no. 4, pp. 391-392, 1981.

[20] M.-J. Schwuger, K. Stickdorn, and R. Schomäcker, "Microemulsions in technical processes," Chemical Reviews, vol. 95, no. 4, pp. 849-864, 1995.

[21] I. Capek, "Preparation of metal nanoparticles in water-inoil (w/o) microemulsions," Advances in Colloid and Interface Science, vol. 110, no. 1-2, pp. 49-74, 2004.

[22] M. A. Malik, M. Y. Wani, and M. A. Hashim, "Microemulsion method: a novel route to synthesize organic and inorganic nanomaterials: 1st Nano Update," Arabian Journal of Chemistry, vol. 5, no. 4, pp. 397-417, 2012.

[23] S. Pramanik and S. C. Bhattacharya, "Size tunable synthesis and characterization of cerium tungstate nanoparticles via $\mathrm{H}_{2} \mathrm{O} / \mathrm{AOT} /$ heptane microemulsion," Materials Chemistry and Physics, vol. 121, no. 1-2, pp. 125-130, 2010.

[24] N. Zamand, A. Nakhaei Pour, M. R. Housaindokht, and M. Izadyar, "Size-controlled synthesis of $\mathrm{SnO}_{2}$ nanoparticles using reverse microemulsion method," Solid State Sciences, vol. 33, pp. 6-11, 2014.

[25] S. A. Hassanzadeh-Tabrizi, S. Shojaei, and M. Ghashang, "Reverse microemulsion synthesis and characterization of $\mathrm{CaSnO}_{3}$ nanoparticles," Ceramics International, vol. 40, no. 7, pp. 9609-9613, 2014.

[26] K. A. Dahlberg and J. W. Schwank, "Synthesis of ${\mathrm{Ni} @ \mathrm{SiO}_{2}}$ nanotube particles in a water-in-oil microemulsion template," Chemistry of Materials, vol. 24, no. 14, pp. 2635-2644, 2012.

[27] R. P. Bagwe and K. C. Khilar, "Effects of intermicellar exchange rate on the formation of silver nanoparticles in reverse microemulsions of AOT," Langmuir, vol. 16, no. 3, pp. 905-910, 2000.
[28] T. Ahmad, R. Chopra, K. V. Ramanujachary, S. E. Lofland, and A. K. Ganguli, "Canted antiferromagnetism in copper oxide nanoparticles synthesized by the reverse-micellar route," Solid State Sciences, vol. 7, no. 7, pp. 891-895, 2005.

[29] J. P. Cason, M. E. Miller, J. B. Thompson, and C. B. Roberts, "Solvent effects on copper nanoparticle growth behavior in AOT reverse micelle systems," The Journal of Physical Chemistry B, vol. 105, no. 12, pp. 2297-2302, 2001.

[30] A. K. Ganguli, A. Ganguly, and S. Vaidya, "Microemulsionbased synthesis of nanocrystalline materials," Chemical Society Reviews, vol. 39, no. 2, pp. 474-485, 2010.

[31] M. P. Pileni, "Fabrication and physical properties of self organized silver nanocrystals," Pure and Applied Chemistry, vol. 72, no. 1-2, pp. 53-65, 2000.

[32] F. Pagnanelli, G. Granata, E. Moscardini, and L. Toro, "Synthesis of $\mathrm{MnCO}_{3}$ nanoparticles by microemulsions: statistical evaluation of the effects of operating conditions on particle size distribution," Journal of Nanoparticle Research, vol. 15, article 1887, 2013.

[33] G. Alonso-Nuñez, J. Lara-Romero, F. Paraguay-Delgado, F. M. Sáchez-Castanñeda, and S. Jiménez-Sandoval, “Temperature optimization of CNT synthesis by spray pyrolysis of alpha-pinene as the carbon source," Journal of Experimental Nanoscience, vol. 5, no. 1, pp. 52-60, 2010.

[34] R. P. Bagwe and K. C. Khilar, "Effects of the intermicellar exchange rate and cations on the size of silver chloride nanoparticles formed in reverse micelles of AOT," Langmuir, vol. 13, no. 24, pp. 6432-6438, 1997.

[35] N. Tian, Z.-Y. Zhou, and S.-G. Sun, "Platinum metal catalysts of high-index surfaces: from single-crystal planes to electrochemically shape-controlled nanoparticles," The Journal of Physical Chemistry C, vol. 112, no. 50, pp. 19801-19817, 2008.

[36] R. Gómez, V. Climent, J. M. Feliu, and M. J. Weaver, “Dependence of the potential of zero charge of stepped platinum (111) electrodes on the oriented step-edge density: electrochemical implications and comparison with work function behavior," The Journal of Physical Chemistry B, vol. 104, no. 3, pp. 597-605, 2000.

[37] M. D. Maciá, J. M. Campiña, E. Herrero, and J. M. Feliu, “On the kinetics of oxygen reduction on platinum stepped surfaces in acidic media," Journal of Electroanalytical Chemistry, vol. 564, no. 1-2, pp. 141-150, 2004.

[38] Y. Köseoğlu, "Structural and magnetic properties of Cr doped NiZn-ferrite nanoparticles prepared by surfactant assisted hydrothermal technique," Ceramics International, vol. 41, no. 5, pp. 6417-6423, 2015.

[39] K. A. Wepasnick, B. A. Smith, K. E. Schrote, H. K. Wilson, S. R. Diegelmann, and D. H. Fairbrother, "Surface and structural characterization of multi-walled carbon nanotubes following different oxidative treatments," Carbon, vol. 49, no. 1, pp. 24-36, 2011.

[40] A. Staykov, Y. Ooishi, and T. Ishihara, "Immobilizing metal nanoparticles on single wall nanotubes. Effect of surface curvature," The Journal of Physical Chemistry C, vol. 118, no. 17, pp. 8907-8916, 2014.

[41] C. Petit, P. Lixon, and M.-P. Pileni, "In situ synthesis of silver nanocluster in AOT reverse micelles," The Journal of Physical Chemistry, vol. 97, no. 49, pp. 12974-12983, 1993.

[42] S. Wang, S. P. Jiang, T. J. White, J. Guo, and X. Wang, "Electrocatalytic activity and interconnectivity of Pt nanoparticles on multiwalled carbon nanotubes for fuel cells," The Journal of Physical Chemistry C, vol. 113, no. 43, pp. 18935-18945, 2009. 
[43] J. N. Solanki and Z. V. P. Murthy, "Controlled size silver nanoparticles synthesis with water-in-oil microemulsion method: a topical review," Industrial and Engineering Chemistry Research, vol. 50, no. 22, pp. 12311-12323, 2011.

[44] J.-S. Zheng, T. Tian, Y. Gao, Q. Wu, J.-X. Ma, and J.-P. Zheng, "Ultra-low Pt loading catalytic layer based on buckypaper for oxygen reduction reaction," International Journal of Hydrogen Energy, vol. 39, no. 25, pp. 13816-13823, 2014.

[45] S. Ghosh and C. R. Raj, "Facile in situ synthesis of multiwall carbon nanotube supported flowerlike pt nanostructures: an efficient electrocatalyst for fuel cell application," The Journal of Physical Chemistry C, vol. 114, no. 24, pp. 10843-10849, 2010.

[46] M. Shao, A. Peles, and K. Shoemaker, "Electrocatalysis on platinum nanoparticles: particle size effect on oxygen reduction reaction activity," Nano Letters, vol. 11, no. 9, pp. 3714-3719, 2011.

[47] W. J. Khudhayer, N. N. Kariuki, X. Wang, D. J. Myers, A. U. Shaikh, and T. Karabacak, "Oxygen reduction reaction electrocatalytic activity of glancing angle deposited platinum nanorod arrays," Journal of the Electrochemical Society, vol. 158, no. 8, pp. B1029-B1041, 2011.

[48] S. Shrestha, S. Asheghi, J. Timbro, and W. E. Mustain, “Temperature controlled surface chemistry of nitrogen-doped mesoporous carbon and its influence on Pt ORR activity," Applied Catalysis A: General, vol. 464-465, pp. 233-242, 2013.

[49] M. H. Leea and J. S. Do, "Kinetics of oxygen reduction reaction on $\mathrm{Co}_{\text {richcore }}-\mathrm{Pt}_{\text {richshell }} / \mathrm{C}$ electrocatalysts," Journal of Power Sources, vol. 188, no. 2, pp. 353-358, 2009.

[50] Y. Sun, Y.-C. Hsieh, L.-C. Chang, P.-W. Wu, and J.-F. Lee, "Synthesis of $\mathrm{Pd}_{9} \mathrm{Ru} @ \mathrm{Pt}$ nanoparticles for oxygen reduction reaction in acidic electrolytes," Journal of Power Sources, vol. 277, pp. 116-123, 2015.

[51] A. Kong, Y. Kong, X. Zhu, Z. Han, and Y. Shan, "Ordered mesoporous $\mathrm{Fe}$ (or $\mathrm{Co}$ )-N-graphitic carbons as excellent nonprecious-metal electrocatalysts for oxygen reduction," Carbon, vol. 78, pp. 49-59, 2014.

[52] N. M. Markoví and P. N. Ross Jr., "Surface science studies of model fuel cell electrocatalysts," Surface Science Reports, vol. 45, no. 4-6, pp. 117-229, 2002.

[53] C. Wang, H. Daimon, T. Onodera, T. Koda, and S. Sun, "A general approach to the size- and shape-controlled synthesis of platinum nanoparticles and their catalytic reduction of oxygen," Angewandte Chemie-International Edition, vol. 47, no. 19, pp. 3588-3591, 2008.

[54] Y. Liu, L. Zhang, B. G. Willis, and W. E. Mustain, "Importance of particle size and distribution in achieving high-activity, highstability reduction catalysts ," ACS Cataysis, vol. 5, no. 3, pp. 1560-1567, 2015. 

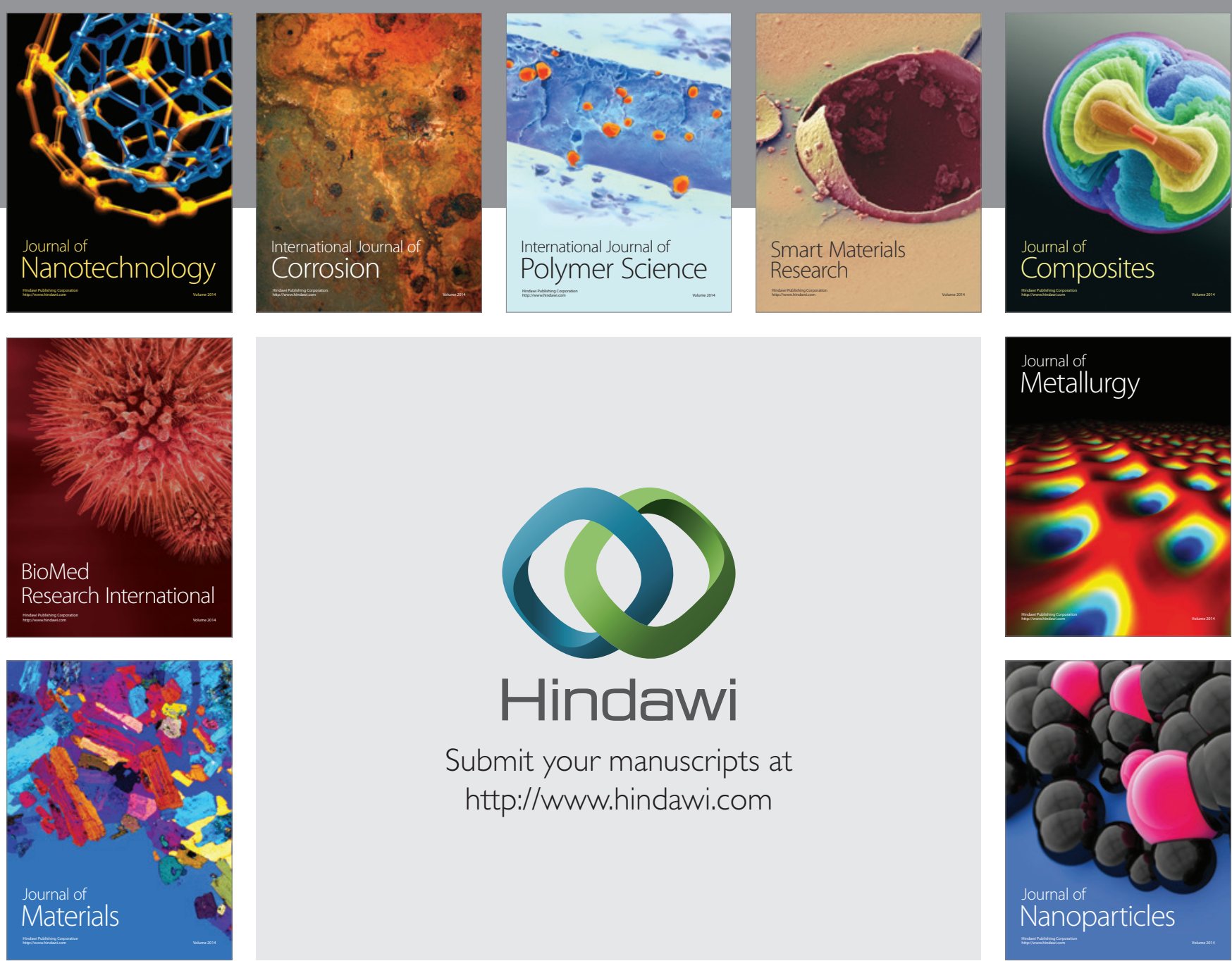

\section{Hindawi}

Submit your manuscripts at

http://www.hindawi.com

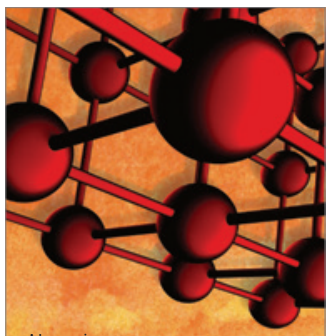

Materials Science and Engineering
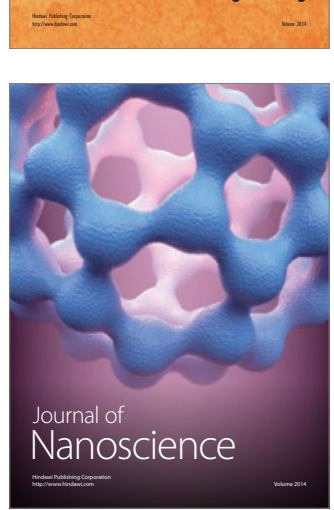
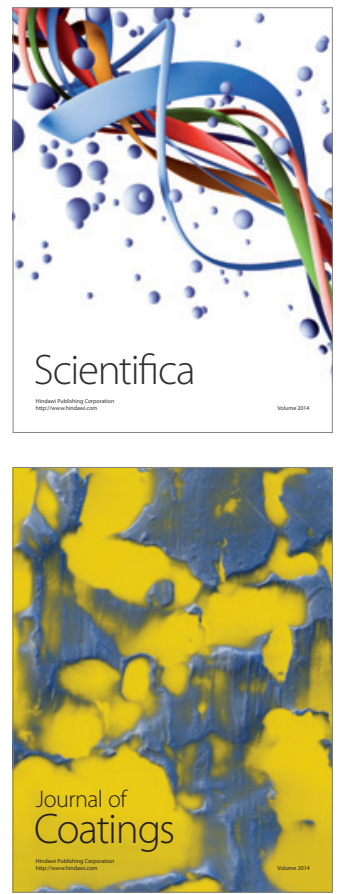
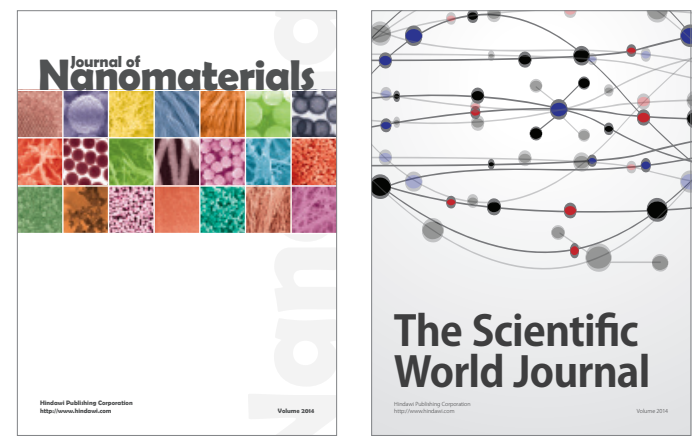

The Scientific World Journal
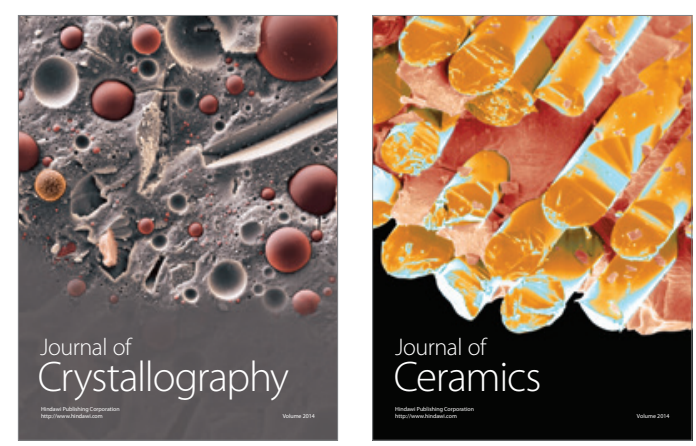
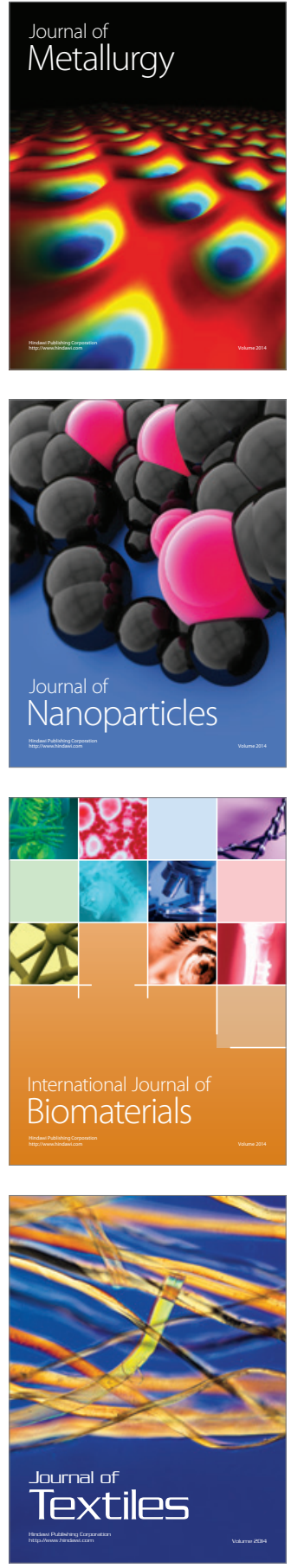